\title{
Diagnosis and Treatment of Post-Cholecystectomy Iatrogenic Biliary Injury: A Retrospective Study
}

\author{
MICHAEL W. SHAKER, M.Sc.; MOHAMED FAYEK, M.D. and ABD M. EZZAT, M.D. \\ The Department of General Surgery, Faculty of Medicine, Ain Shams University
}

\begin{abstract}
Background: Preventive strategies and safe surgery are of utmost importance to minimize BDI during cholecystectomy. The impor-tance of frank communication with the patient and accurate documentation cannot be overemphasized. Diagnosis requires a high index of suspicion with focused clinical, biochemical, and radiological examination.

Aim of Study: Is to evaluate the best protocol in management of iatrogenic biliary injuries sustained during either laparoscopic or open cholecystectomy.

Patients and Methods: 40 patients with iatrogenic bile duct injuries following cholecystectomy (open and Laparoscopic) referred to the Department of Hepatobiliary Surgery at Sohag Teaching Hospital, Sohag Univeristy, Egypt from January 2016 to January 2018 and treated by multidisciplinary approach team including hepatobiliary surgeons, gastroenterologists, and interventional radiologists.
\end{abstract}

Results: In this retrospective study there were 12 cases that detected intraoperatively; 2 cases of them with complete cut of CBD. 8 cases $(66,67 \%)$ with partial injury of CBD and the other 2 cases (16.67\%) with partial injury of CHD; 9 cases were repaired by primary repair of CBD and 3 cases by repair over stent. There were 14 cases detected early postoperative $1(7.14 \%)$ case with complete injury of CBD and $4(28.57 \%)$ cases with with partial injury of CBD and 6 $(42.86 \%)$ cases with ligation of CBD and one $(7.14 \%)$ case with slipped cystic duct ligature and 2 cases with ligation of CHD. There were 14 cases were detected late postoperatively 3 cases of them were with slipped cystic duct ligature and 11 cases with stricture of CBD.

Conclusion: Advanced laparoscopic fellowship training may decrease conversion rates of laparoscopic cholecystectomy. This may translate into a slightly shorter duration of hospitalization for these patients, which for a high volume procedure could make a significant impact on hospital economics.

Key Words: Cholecystectomy - Iatrogenic biliary Injury.

Correspondence to: Dr. Michael W. Shaker, The Department of General Surgery, Faculty of Medicine, Ain Shams University

\section{Introduction}

IATROGENIC biliary trauma has increased many folds ever since laparoscopic cholecystectomy came into practice. Associated morbidity, mortality and the long term sequel of such injuries have made them the most dreaded complications of laparoscopic cholecystectomy. This has been ascribed to the lack of experience in this new technique. A decline in the rate of iatrogenic biliary trauma expected with passage of time [1].

A number of mechanisms were postulated including an undue dissection in a distorted Calot's triangle, use of diathermy close to bile ducts, local pathology such as acute and chronic inflammation with fibroses gallbladder, excessive traction on gallbladder, a casual attitude during surgery and human error [2].

The diagnostic evaluation of the patient with biliary injuries should include accurate determination of the biliary anatomy. Many studies proposed investigations like intra-operative cholangiography and magnetic resonance cholangiogram to reduce the rate [3].

Early recognition of iatrogenic biliary injury is essential in any patient who has an atypical course following cholecystectomy to prevent major morbidity Accordingly, Imaging techniques, such as Ultrasound and CT, are extremely valuable during the initial evaluation of a patient of having a biliary injury.

ERCP can confirm the presence of biliary injury and provides a means for definitively managing many injuries with temporary internal stents. If complete disruption or occlusion of the proximal bile duct is present, prompt evaluation with Percutaneous Transhepatic Cholangiography (PTC) is 
necessary to define the biliary anatomy and decompress the biliary system [4].

Non invasive imaging techniques, such as Magnetic Resonance Cholangio pancreatography (MRCP) and CT cholangiography can be used to evaluate bile duct injuries. CT cholangiography has also been shown to be an effective means of imaging the biliary tree. Too much debate about the treatment of iatrogenic biliary injury is still present. Endoscopic intervention can be safe and effective method of treatment in some cases and surgery can be the treatment of choice in some cases. However, management should be individualized based on factors such as outpatients or inpatients, presence of stone, stricture, ligature, or coagulopathy [5]

The surgical treatment of elective IBDI is made using different methods of biliary reconstructions. The main aim of surgical treatment is the reconstruction of proper flow of bile to the alimentary tract. The following operations are performed in biliary injuries surgical treatment: Roux-Y hepaticojejunostomy, end-to-end ductal biliary anastomosis with tube drainage choledochoduodenostomy, hepaticojejunostomy, jejunal interposition hepticoduodenostomy [6].

To prevent post cholecystectomy biliary duct injury morbidity and mortality, a long way we have to walk over. And such purposes have been introduced in our dictionary since the increasing bulk of people who have many surgical interventions nowadays.

\section{Aim of the work:}

The aim of this work is to evaluate the best protocol in management of iatrogenic biliary injuries sustained during either laparoscopic or open cholecystectomy.

\section{Patients and Methods}

This retrospective study included 40 patients with iatrogenic bile duct injuries following cholecystectomy (open and Laparoscopic) referred to the Department of Hepatobiliary Surgery at Sohag Teaching Hospital, Sohag Univeristy, Egypt from January 2016 to January 2018 and treated by multidisciplinary approach team including hepatobiliary surgeons, gastroenterologists, and interventional radiologists. The multidisciplinary team was established after ethical and scientific approval from Hepatobiliary Department. All cases of iatrogenic bile duct injuries should undergo this multidisciplinary team approach to set up a road map management of such cases.
All patients complained of postcholecystectomy biliary tract injuries encountered with variable presentation and timing from the surgical insult. Cases were subjected to the following: Thorough detailed history taking and meticulous clinical examination.

Operative details of the previous cholecystectomy should be revised with surgical team of referring hospital.

Investigation needed to diagnose the problems such as liver function tests and abdominal ultrasound were done for all cases as routine preliminary workup. Computed tomography or magnetic resonance imaging was done in some cases. Cholangiogram was done for all cases (the gold standard evaluation of biliary injuries) as a trans-tube cholangiogram (with a T-tube in place), an endoscopic cholangiography endoscopic retrograde cholangiopancreatography (ERCP) in most cases, or percutaneous transhepatic cholangiogram in some selected cases in which endoscopic approaches failed.

After receiving patients data by multidisciplinary team, patient condition was categorized through discussion of detailed results of treatment for each category to reach consensus on which type of modality to start with, either endoscopy or intervention radiology as minimal techniques for definitive treatment or bridging technique for definitive surgery (as complementary tool) prior to surgery or whether surgery still is needed for definitive treatment or surgery is mandatory from the start as definitive treatment.

Also the multidisciplinary team approach gave an outreach service for on-table repair of iatrogenic bile duct injuries to nearby hospitals around the tertiary center in 19 cases after receiving emergency call from the surgical team in those hospitals.

Patients were categorized according to the presentation into the biliary leakage group and the biliary stricture group as diagnosed by previous tools. Each group was managed according to the road map made by multidisciplinary team, starting with the minimally invasive tools (endoscopic treatment alone or in addition to percutaneous interventional radiological manipulation in difficult cases) to more invasive surgical treatment.

Biliary leakage group classified according to the classification of Strasberg et al., was managed by endoscopic sphincterotomy in mild cases and/or stenting in moderate to major leakage, with concomitant stone extraction if present with the common bile duct (CBD) by ERCP. 
Biliary stricture group categorized according to the classification of Strasberg et al., was treated initially by endoscopic dilatation and stenting in repeated endoscopic sessions, with upgrading of the stent, until cure was obtained (after full dilatation of the stricture segment as evident by loss of the waist in the cholangiogram).

Percutaneous manipulation was attempted in cases of proximal biliary injuries as in major CBD injuries, transaction, or ligation through percutaneous transhepatic cholangiogram as diagnostic tool prior to surgery, percutaneous manipulations, and guide wire deployment through the CBD prior to combined procedures (Rendezvous) techniques or percutaneous dilatation and stenting for stricture or injuries.

Surgical approaches: Surgical intervention was attempted for the cases not fixed by endoscopy or interventional radiology or cases which deserved surgical intervention from the start (transection, ligation, fibrotic stricture of $\mathrm{CBD}$, and postoperative stenotic stricture in bilioenteric anastomosis (redo operation), with the following surgical maneuvers:, Emergency surgery for peritoneal lavage and drainage of biliary peritonitis, on table repair of iatrogenic bile duct injuries in cases diagnosed intraoperatively in our center or as an outreach service in nearby hospitals, Primary repair on T-tube splint in a minor laceration injury of the CBD, Choledocholithotomy procedure in associated CBD stones and Undoing CBD ligation.

Bilioenteric anastomosis operations were done as a Roux-En-Y loop depending upon the site of injury, in proximal injuries in porta hepatis (HeppCouinaud technique), was capitalized on the extrahepatic course of the left main hepatic duct. Hepaticojejunostomy was done (for the injuries above the biliary confluence) in which the repair was done in the common hepatic duct or at the bile duct confluence with widening the stoma by opening the right and left bile ducts together at site of confluence (stomaplasty), or choledochojejunostomy was done (in the injuries below the cystic duct insertion and the proximal bile and hepatic duct was not cicatrized or infected). The bilioenteric anastomosis may be side to side or end to side maneuvers depending upon the site and extent of the biliary injuries, and the anastomosis was tension free, mucosa to mucosa, and good wide stoma, with T-tube or biliary splint (specially small ducts) in majority of the cases to decompress the biliary tree in the immediate post-operative period and to obtain postoperative, contrast studies.

\section{Statistical analysis:}

Data were analyzed using STATA intercooled version 12.1. Quantitative data was represented as mean, standard deviation, median and range. Data was analyzed using ANOVA for comparison of the means of three groups. When the data was not normally distributed Kruskal Wallis test was used. Qualitative data was presented as number and percentage and compared using Chi square test. Graphs were produced by using Excel or STATA program. $p$-value was considered significant if it was less than 0.05 .

\section{Results}

Table (1): Patients' characteristic.

\begin{tabular}{cl}
\hline Characteristic & Summary characteristics \\
\hline Age/year: & $39.53(11.85)$ \\
Mean (SD) & $39(20-60)$ \\
Median (range) & \\
Gender: & $27(67.50 \%)$ \\
Females & $13(32.50 \%)$ \\
Males & \\
Address: & $4(10.00 \%)$ \\
Aswan & $3(7.5 \%)$ \\
Asyiut & $1(2.50 \%)$ \\
Luxor & $5(12.50 \%)$ \\
Qena & $27(67.50 \%)$ \\
Sohag &
\end{tabular}

Table (2): Time of intervention of studied population.

\begin{tabular}{ll}
\hline Time of intervention & Summary statistics \\
\hline Intraoperative & $12(30.00 \%)$ \\
Early postoperative & $14(35 \%)$ \\
Late postoperative & $14(35 \%)$ \\
\hline
\end{tabular}

Table (3): Demographic characteristic of studied population.

\begin{tabular}{lllll} 
& & \multicolumn{2}{c}{ Early } & Late \\
Characteristic & $\begin{array}{c}\text { Intraoperative } \\
\mathrm{N}=12\end{array}$ & $\begin{array}{c}p^{-} \\
\text {postoperative } \\
\mathrm{N}=14\end{array}$ & $\mathrm{~N}=14$ & \\
\hline Agelyear: & & & & \\
Mean (SD) & $32.83(8.21)$ & $39.43(14.49)$ & $45.36(8.72)$ & 0.02 \\
Median (range) & $37(21-44)$ & $41(20-60)$ & $44.5(32-58)$ & \\
vender: & & & & \\
Females & $11(91.67 \%)$ & $8(57.14 \%)$ & $8(57.14 \%)$ & 0.10 \\
Males & $1(8.33 \%)$ & $6(42.86 \%)$ & $6(42.86 \%)$ & \\
Address: & & & & 0.58 \\
Aswan & $2(16.67 \%)$ & $1(7.14 \%)$ & $1(7.14 \%)$ & \\
Asyiut & $2(16.67 \%)$ & 0 & $1(7.14 \%)$ & \\
Luxor & 0 & 0 & $1(7.14 \%)$ & \\
Qena & $1(8.33 \%)$ & $3(21.43 \%)$ & $1(7.14 \%)$ & \\
Sohag & $7(58.33 \%)$ & $10(71.43 \%)$ & $10(71.43 \%)$ & \\
\hline
\end{tabular}


Table (4): Anthropometric measurements of studied population.

\begin{tabular}{lllll}
\hline $\begin{array}{l}\text { Anthropometric } \\
\text { measurements }\end{array}$ & $\begin{array}{c}\text { Intraoperative } \\
\mathrm{N}=12\end{array}$ & $\begin{array}{c}\text { Early } \\
\text { postoperative } \\
\mathrm{N}=14\end{array}$ & $\begin{array}{c}\text { Late } \\
\text { postoperative } \\
\mathrm{N}=14\end{array}$ & $\begin{array}{c}p \text { - } \\
\text { value }\end{array}$ \\
\hline BMI: & & & \\
Mean (SD) & $27.82(5.16)$ & 34.26 & 23.45 \\
Median (range) & $26.17(20.55-35.65)$ & $27.05(20.57-33.29)$ & $26.86(21.88-33.22)$ \\
\hline
\end{tabular}

Table (5): Investigations of studied population.

\begin{tabular}{|c|c|c|c|c|}
\hline Investigations & $\begin{array}{l}\text { Intraoperative } \\
\qquad \mathrm{N}=12\end{array}$ & $\begin{array}{c}\text { Early } \\
\text { postoperative } \\
\mathrm{N}=14\end{array}$ & $\begin{array}{c}\text { Late } \\
\text { postoperative } \\
\mathrm{N}=14\end{array}$ & $\begin{array}{c}p- \\
\text { value }\end{array}$ \\
\hline \multicolumn{5}{|l|}{ Hemoglobin: } \\
\hline Mean (SD) & $9.64(1.41)$ & $10.51(1.79)$ & $11.32(1.60)$ & \\
\hline Median (range) & $11.5(9.9-14)$ & $10.75(9-15)$ & $11.8(8-14)$ & \\
\hline \multicolumn{5}{|l|}{ WBCs: } \\
\hline Mean (SD) & $8542(3001)$ & $13742(2495)$ & $6521(3245)$ & \\
\hline Median (range) & $6750(4000-13000)$ & $8450(3500-12700)$ & $6250(3400-14000)$ & \\
\hline \multicolumn{5}{|l|}{ Total bilirubin: } \\
\hline Mean (SD) & $1.08(0.25)$ & $4.32(2.09)$ & $5.71(2.98)$ & 0.0001 \\
\hline Median (range) & $1(0.8-1.5)$ & $5(0.8-7)$ & $6.25(1-11)$ & \\
\hline \multicolumn{5}{|l|}{ Direct bilirubin: } \\
\hline Mean (SD) & $0.38(0.31)$ & $3.44(1.92)$ & $4.9(2.67)$ & 0.0001 \\
\hline Median (range) & $0.2(0.2-1)$ & $4(0.2-6.5)$ & $5.5(0.2-9)$ & \\
\hline \multicolumn{5}{|l|}{ Creatinine: } \\
\hline Mean (SD) & $0.93(0.31)$ & $0.88(0.47)$ & $1.01(0.42)$ & 0.60 \\
\hline Median (range) & $0.95(0.4-1.5)$ & $0.75(0.3-2)$ & $0.9(0.5-1.9)$ & \\
\hline \multicolumn{5}{|l|}{ AST: } \\
\hline Mean (SD) & $50.65(14.41)$ & $74(24.70)$ & $39(19.66)$ & \\
\hline Median (range) & $44.5(24-72)$ & $60(28-11)$ & $62(25-88)$ & \\
\hline \multicolumn{5}{|l|}{$A L T:$} \\
\hline Mean (SD) & $75(16.84)$ & $90(22.46)$ & $64(16.14)$ & \\
\hline Median (range) & $63(24-85)$ & $78(37-112)$ & $72(30-95)$ & \\
\hline
\end{tabular}

Table (6): Intraoperative findings of studied population.

\begin{tabular}{|c|c|c|c|c|}
\hline Intraoperative findings & $\begin{array}{l}\text { Intraoperative } \\
\qquad \mathrm{N}=12\end{array}$ & $\begin{array}{c}\text { Early } \\
\text { postoperative } \\
\mathrm{N}=14\end{array}$ & $\begin{array}{c}\text { Late } \\
\text { postoperative } \\
\mathrm{N}=14\end{array}$ & $\begin{array}{c}p- \\
\text { value }\end{array}$ \\
\hline \multicolumn{5}{|l|}{ Grade of bile duct injury: } \\
\hline Complete cut of CBD & 2 & $1(7.14 \%)$ & 0 & \\
\hline Partial injury of CBD & $8(66.67 \%)$ & $4(28.57 \%)$ & 0 & \\
\hline Partial injury of CHD & $2(16.67 \%)$ & 0 & 0 & \\
\hline Ligation of CBD & 0 & $6(42.86 \%)$ & 0 & \\
\hline Ligation of CHD & 0 & 2 & 0 & \\
\hline Ligation of Rt. HD & 0 & 0 & 0 & \\
\hline Slipped cystic duct ligature or clip & 0 & $1(7.14 \%)$ & 0 & \\
\hline Stricture of CBD & 0 & 0 & 3 & \\
\hline Stricture of CHD & 0 & 0 & 11 & \\
\hline \multicolumn{5}{|l|}{ Associated injuries: } \\
\hline No & $12(100 \%)$ & $11(78.57 \%)$ & $14(100 \%)$ & 0.20 \\
\hline Serosal injury of stomach & 0 & $1(7.14 \%)$ & 0 & \\
\hline Small intestinal injury & 0 & $2(14.29 \%)$ & 0 & \\
\hline \multicolumn{5}{|l|}{ Procedure performed: } \\
\hline 1ry repair of CBD & 9 & 2 & 0 & \\
\hline Choledocoj ejunostomy & 0 & 0 & 3 & \\
\hline Hepaticojejunostomy rouxeny & 0 & 9 & 11 & \\
\hline Peritoneal lavage with drainage of peritonitis & 0 & $1(7.14 \%)$ & 0 & \\
\hline Repair over a stent & 0 & 0 & 0 & \\
\hline Repair over $t$ tube & 3 & 2 & 0 & \\
\hline
\end{tabular}


Table (7): Postoperative follow-up of studied population.

\begin{tabular}{|c|c|c|c|c|}
\hline Postoperative findings & $\begin{array}{c}\text { Intraoperative } \\
\quad \mathrm{N}=12\end{array}$ & $\begin{array}{c}\text { Early } \\
\text { postoperative } \\
\mathrm{N}=14\end{array}$ & $\begin{array}{l}\text { Late } \\
\text { postoperative } \\
\mathrm{N}=14\end{array}$ & $\begin{array}{c}p- \\
\text { value }\end{array}$ \\
\hline $\begin{array}{l}\text { Complication: } \\
\text { No } \\
\text { Yes }\end{array}$ & $\begin{array}{l}12(100 \%) \\
0\end{array}$ & $\begin{array}{l}8(57.14 \%) \\
6(42.86 \%)\end{array}$ & $\begin{array}{l}14(100 \%) \\
0\end{array}$ & 0.001 \\
\hline $\begin{array}{l}\text { Need for re-operation: } \\
\text { No } \\
\text { Yes }\end{array}$ & $\begin{array}{l}12(100 \%) \\
0\end{array}$ & $\begin{array}{l}10(71.43 \%) \\
4(28.57 \%)\end{array}$ & $14(100 \%)$ & 0.02 \\
\hline $\begin{array}{l}\text { Normalization of AST (days): } \\
\quad \text { Mean (SD) } \\
\text { Median (range) }\end{array}$ & $\begin{array}{l}1.5(0.64) \\
1.25(1-2.5)\end{array}$ & $\begin{array}{l}2.21(0.80) \\
2(1-4)\end{array}$ & $\begin{array}{l}1.5(0.52) \\
1.5(1-3)\end{array}$ & 0.04 \\
\hline $\begin{array}{l}\text { Normalization of Bilirubin (days): } \\
\text { Mean (SD) } \\
\text { Median (range }\end{array}$ & $\begin{array}{l}2.06(1.16) \\
1.6(1-4.6)\end{array}$ & $\begin{array}{l}3.14(1.03) \\
3(2-5)\end{array}$ & $\begin{array}{l}2.07(0.73) \\
2(1-3)\end{array}$ & 0.01 \\
\hline $\begin{array}{l}\text { ICU stay: } \\
\text { No } \\
\text { Yes }\end{array}$ & $\begin{array}{l}12(100 \%) \\
0\end{array}$ & $\begin{array}{l}10(71.43 \%) \\
4(28.57 \%)\end{array}$ & $\begin{array}{l}14(100 \%) \\
0\end{array}$ & 0.02 \\
\hline $\begin{array}{l}\text { Hospital stay: } \\
\text { Mean (SD) } \\
\text { Median (range }\end{array}$ & $\begin{array}{l}3.58(1.37) \\
3(2-7)\end{array}$ & $\begin{array}{l}7.79(1.67) \\
7.5(5-10)\end{array}$ & $\begin{array}{l}4.57(1.28) \\
4(3-7)\end{array}$ & 0.008 \\
\hline $\begin{array}{l}\text { Outcome: } \\
\text { Alive } \\
\text { Dead }\end{array}$ & $\begin{array}{l}12(100 \%) \\
0\end{array}$ & $\begin{array}{l}13(78.57 \%) \\
3(21.43 \%)\end{array}$ & $\begin{array}{l}14(100 \%) \\
0\end{array}$ & 0.049 \\
\hline
\end{tabular}

\section{Discussion}

In our study, only one patient underwent US guided aspiration of bile collection successfully. Show et al., advocated this technique and considered it superior to doing an unnecessary laparotomy for the patients. ERCP was successfully preformed as a preoperative diagnostic investigation in $87.5 \%$ of the patients in our study. Similar results were seen in the study by Martin et al., where $88 \%$ of their patients successfully underwent preoperative diagnostic ERCP [7].

It was noticed in our study that ERCP failed in one patient to assess the biliary tree, most probably owing to extensive stricture of bile ducts with severe fibrosis which pulls the proximal stump to a much higher level and pulling the distal stump. Diagnostic workup and treatment of bile duct injuries need a multidisciplinary approach requiring gastroenterologists, radiologists, and surgeon [8].

These results are also comparable with those of Martin et al., who had a success rate of $89 \%$. The endoscopic treatment succeeded in all five patients to give the desired therapy with closure of the fistula and complete relieve of jaundice in all five patients within 2 weeks. The fistula was closed after 10 days in one patient, after 2 weeks in two patients, and after 20 days in other two patients. During the period of follow-up (mean 9 months), there was no recurrence of fistula or jaundice [9].

In the study by Misra et al., 32\% of their patients successfully underwent PTC as the preoperative diagnostic measure. PTC is helpful in identifying the proximal extent of complete segmental andmajor bile duct injuries and obstruction but can cause complications such as cholangitis, bile leakage, and even hemorrhage. MRCP was done for eight (32\%) patients in our study (nevertheless, it was of excellent standard in determining the exact site of stricture and in demonstration of the exact anatomy of the proximal biliary tree) [10]

In our study, it had a diagnostic accuracy of $100 \%$. In a study performed by Hakansson et al., MRC provided additional information that may not be available by PTC in delineating complete anatomy and injury of biliary tract. In our study, $82 \%$ of the patients underwent surgical corrective procedures for their bile duct injuries [11].

Persistence of symptoms after cholecystectomy may be due to retained stones or regeneration of stones in the remnant gallbladder. This usually takes the form of right upper quadrant abdominal pain and dyspepsia, with or without jaundice. The causes of post-cholecystectomy syndrome are often non-biliary like peptic ulcer, gastroesophageal reflux, pancreatic disorders, liver diseases, irritable bowel and coronary artery disease [12]. 
There may also be gender-specific risk factors for developing symptoms after cholecystectomy. Bodvall and Overgaard found that the incidence of recurrent symptoms among female patients was $43 \%$, compared to $28 \%$ among male patients. Several reports have proposed that a cystic duct remnant $>1 \mathrm{~cm}$ in length after cholecystectomy may be responsible, at least in part, for post-cholecystectomy syndrome, other authors refute this [13].

Residual gallstones are more often reported in cystic duct remnants. The possible etiology of such an occurrence is often a failure to define the cystic duct, CBD junction. This is more likely to occur in the presence of acute local inflammation or fibrosis. It may be prudent to dissect the cystic duct up to the common duct defining their junction in selected patients [14].

Patients at increased risk of harboring stones in the cystic duct are patients with a history of biliary colics, pancreatitis, obstructive jaundice and those having undergone therapeutic ERCP prior to clipping and dividing the cystic duct. Stones in the cystic duct may be evident on visualization or may also be palpated with the dissector [15].

Adhesions around the cystic duct may be another indicator of an impacted stone within it. In these circumstances, dissection should continue proximal to the stone towards junction of the cystic duct and CBD. With increasing experience, it is almost always possible to apply clips on the cystic duct proximal to the stone. No attempt should be made to 'milk' the stone distally, as such a maneuver may fragment the stone that may pass into the common duct and lead to biliary colic in the postoperative period [16].

Incomplete gallbladder removal during cholecystectomy may be both voluntary and inadvertent. Kuster and Domagk recommend a temporary laparoscopic cholecystostomy followed by delayed laparoscopic cholecyst-ectomy as an alternative to conversion to open cholecystectomy in acute cholecystitis [17]

Subtotal cholecystectomy has been recommended as a safe and viable option in patients where anatomical distortion at Calot's triangle precludes a safe dissection. Conversion rate to open surgery is higher for patients with acute cholecystitis than in those without acute cholecystitis. Laparoscopic subtotal cholecystectomy has been suggested as an alternative to decrease this conversion rate [18]
ERCP is popular as a diagnostic and therapeutic tool in managing extrahepatic biliary pathology. However, it is an invasive investigation and associated with a specific procedure related complications. The main advantage of MRCP is its noninvasiveness, absence of sedation and avoidance of radiation exposure. Its sensitivity and specificity are similar to EUS [19].

The bile duct may also be injured by excessive diathermy, resulting in a bile leak or a stricture Insecure clipping of the cystic duct may also result in bile leakage. If these injuries are not at the time of surgery, they present as a colleague lections or jaundice postoperatively. ERCP will delineate the exact injury accurately. These injuries are preventable by careful attention to technique and a willingness to convert to open surgery when difficulties are encountered. To mini-mize the risk to patients, programs of training, proctoring, and accreditation in laparoscopic surgery should be established [20]

In our study, all patients had excellent recovery and were discharged in a good condition within 10 days of surgery; however, long-term follow-up was not available. Strictures may develop early (within days or weeks) or may take years to develop and vary in both diameter and length [21]

Early strictures may develop due to intraoperative procedures such as clamping, ligation or clipping of the duct or thermal injury. Local infection may also result in both early and delayed stricture formation.Thermal injury and occult malignancy are important causes of delayed stricture formation [22].

A thorough knowledge of the anatomy of the region, including possible anomalies, is important in preventing iatrogenic bile duct injuries. Both open cholecystectomy and LC are based on similar operative principles. Proper exposure and visualization, careful dissection, adequate haemostasis, careful placement of ligatures and clips, and division of structures only after proper identification are essential for safe cholecystectomy [23].

Fundus-first cholecystectomy is well recognized as a safe technique during open cholecystectomy as well as during LC, because it minimizes the risk of injuries to the biliary structures at the Calot's triangle. Further specialised training to heighten awareness of the possible problems relating to the anatomy of the Calot's triangle is essential, not only for trainees but also for consultants engaged in this field [24]. 
In recent studies it has been demonstrated that the basic cause of error is not the inexperience of the surgeon, but the use of an improper approach in relation to the extrahepatic biliary tree due to a visual perceptual illusion. In reference to IOC in the scientific literature, there are many opinions about its routine or selective use, especial-ly concerning the incidence of bile duct injury and missed CBD stones [25].

This method, however, is burnened by morbidity and should only be performed in facilities where the necessary equipment and experience are available. With regard to missed CBD stones, surgeons who support the routine use of IOC claim that asymptomatic CBD stones constitute about $10 \%$ of patients, and up to $2 \%$ show no signs of the disease, as is revealed by elevated liver function tests, dilated bile duct on ultrasonography, and a history of jaundice or pancreatitis [26]

In the current study, 2 cases $(0.18 \%)$ of major bile duct injuries have been reported, which is a comparable rate to that of other similar reports ranging from 0.05 to $0.5 \%$. Bile leakage represented $0.27 \%$ and missed CBD stones were found in 4 patients $(0.36 \%)$ - data comparable to that of other studies.

Bile Duct Injury during LC without IOC lecystectomy in doubtful cases. In the presence of acute or chronic cholecystitis, obesity, liver cirrhosis, previous surgery with extensive adhesions, anatomic variations, and intraoperative bleeding, the surgeon must not hesitate when considering conversion to open approach; there is no substitute for experience and caution in biliary surgery [27]

Bile-duct injury and bile leak are important considerations in patients who develop difficulties in the early postoperative period following laparoscopic cholecystectomy. Postoperative col-lections are common and of no clinical concern if found incidentally in an asymptomatic tent However, when clinical symptoms such as abdominal pain, fever, jaundice, or leukocytosis are present, a biliary injury should be considered ered [28].

Sonography and CT are helpful in detect abdominal fluid flow collections but can not differentiate bile from other fluids. Hepatobiliary scintigraphy is very useful in these patients, often showing disruption of the biliary tree without the need for invasive intervention. PTC and ERCP further defines the exact site of biliary injury, and have the added advantage of offering nonoperative management for most injuries except complete bile-duct transection [29].
Bile duct injuries have become commoner in recent years. The overall acceptance of laparoscopic cholecystectomy you have increased the number of operations performed for gall-bladder disease worldwide. Compared with open operationt ion, the prevalence of duct injury is greater when laparoscopy is employed but the difference has not the statistical significance Several recommendations have been put forward to reduce the risk of bile duct injury, yet the accident continues to occurith an incidence of $0.3-0.6 \%$ in many centers [30]

A major bile duct injury resulting from LC is a problem with substantial cost to the health care system. Savader et al., reported that treatment for LC-related bile duct injuries can be 4.5 to 26 times the cost of an uncomplicated procedure and carries a significant rate of morbidity and mortality. However intraoperative recognition of such an injury, with immediate conversion to an open procedure for definitive repair, can result in significant cost saving and relates directly to decreased morbidity, mortality, length of hospitalization, and number of operative care days [31]

The role of routine intraoperative cholangiography in preventing the biliary injury has been controversial, with some reports claiming that it lowers the risk of injury and others refuting this claim. Still others report that although cholangiography does not lower the risk of biliary injury directly, it allows early recognition and prevents further extension of the injury [32]

Literature on predisposing factors for biliary injury during LC suggests that the presence of acute cholecystitis has the strongest correlation. However, some reports say this may not be true. Ooi et al., reported a retrospective review of 4,445 laparoscopic cholecystec-tomies with 19 biliary injuries $(0.43 \%)$. They found that inflammation at Calot's triangle was an important associated factor for injury [33]

We also included the timing of BDI detection intraop-eratively, either by a bile leak or cholangiography, or the early consequences thereof, such as a biloma, abscess, or biliary peritonitis, or invariably late, resulting in stricture or hepatic atrophy. The importance of this categorization is because management is different according to what has already been done (artery ligation, opening of the bile duct) and the moment when the BDI is detected for example, during the index operation, the immediate postoperative period (often with sepsis), or late (stricture) [34]. 
We chose not to indicate whether the BDI was the consequence of an opening in the main bile duct with the intention of accomplishing or not accomplishing an action, such as inserting a catheter; removing a stone, parasite, or foreign body; or preparing an anastomosis. We had several reasons for this. First, we did not want to use the word intentional, as its definition is not universal. Second, the term has a medicolegal connotation [35].

Percutaneous intervention is performed for biloma and abscess drainage, transhepatic biliary drainage, U-tube placement, dilation of bile duct strictures and stent placement to maintain ductal patency, and management of complications from previous percutaneous interventions. Endoscopic and percutaneous interventional procedures may be performed for defnitive treatment or as adjuncts to defnitive surgical repair [36].

Some authors recommend routine use of IOC; they found that about one third of the BDIs could be prevented using IOC. However, there is much controversy in the literature on the routine use of IOC. Olsen reported a series of 177 BDIs where only 2 of the 32 IOCs performed were interpreted correctly [37].

The definitive therapy for BDI depends on the type of lesion and the timing of its recognition. The rate for intraoperative detection of BDI was $19 \%$ in the present study, whose percentage is well in accordance with earlier reports [38].

Most studies comparing LCs with OCs have been per-formed shortly after the introduction of LC. Nowadays, it is generally accepted that LC is the gold standard operation for uncomplicated gallstone disease and early acute cholecystitis, whereas OC is reserved for the most complex cases, usually in the emergency setting for severe acute cholecystitis [39].

Patients undergoing $\mathrm{OC}$ are usually severely ill, have several comorbidities, and are elderly, whereas patients undergoing LC are substantially healthier and younger and operations are usually done as elective procedures for biliary colic. Therefore, the differences in these patient populations are currently so substantial that any true comparison between them is unjustified [40].

BDI rates are hard to assess even from large single center reports. Our results are in line with rates published from large adult series and data sets. Dolan et al. assessed the National Inpatient Sample and used a strict BDI definition of LC followed by a procedure code representing biliary recon striation in the same hospitalization and quoted an overall rate of $0.15 \%$ in adult patients [41].

Dolan et al., may have an underestimate of BDI as many patients with BDI are referred to specialized centers for management and may be excluded from their analysis which required the LC and the biliary reconstruction to be performed at the same institution [42]

Consequently, Strasberg et al., made the Bismuth classification much more comprehensive by including other types of laparoscopic extrahepatic bile duct injury. Significant postoperative bile leak may occur in up to $1 \%$ of patients undergoing laparoscopic cholecystectomy compared to $0.5 \%$ after open cholecystectomy and is mainly caused by a slipped cystic duct ligature or leak from an accessory or anomalous bile duct. Bile leak usually presents within the first week but can manifest and be diagnosed up to 30 days after surgery; symptoms are unspecific and could be related to other postocepter [43].

Clinical manifestations of bile leak include persistent abdominal tenderness, generalized malaise and anorexia. Bile leak after surgery resulting in intraperitoneal bile collection is typically not contaminated by bacterium and usually does not result in severe bile peritonitis Detecting and locating bile leak may not be easy; patients usually undergo US and CT examinations but these methods can not reliably distinguish bile leak from other postoperative fluid collection such as blood, pus, or serous fluid because of similar densities [44].

Bile leak after laparoscopic cholecystectomy is reported in $0.3 \%-2.7 \%$ of patients. The morbidity and mortality of bile leak is signifcant if not treated promptly. The formation of a communication between a liver abscess and bile duct is an uncommon cause of bile leak. Surgical management of a biliary fstula is associated with high morbidity and mortality [45].

However, because of the rarity of the condition And lack of uniform approach, there is paucity of data in the literature regarding the outcomes of endoscopic approaches in bile leak There has been no study from India previously published in the literature describing the effcacy of endoscopic management in bile leak [46]

The mechanisms and gravity of biliary injuries may therefore differ with laparoscopic cholecystectomy and it is not surprising that approaches to 
treatment may differ also. It is not necessary to adopt the traditional common surgical approach with bilio-enteric anastomosis for all bile duct injuries occurring during laparoseopic cholecystectomy [47].

It was shown that laparoscopic cholecystectomy has signifcantly fewer complications than the open, but the iatrogenic lesions of the biliary tract occur twice or even three times more often. Already the first major multicenter study from Europe and the United States has found such injuries in $0.5 \%$ of patients. The number of biliary tract injury during open cholecystectomy according to various authors is up to $0.2 \%$ [48]

Injury of Luschkin duct is found in $33 \%$ of the patients and it is a frequent complication. The biliary duct injury can be caused by lack of surgeon experience performing laparoscopy, but the cause may be difficult operating findings, such as gangrenous, acutely infamed or atrophic gallbladder, which is a consequence of long-term chronic infammation [49]

Biliary complications are reported in many studies. The extra-biliary complications do occur with almost the same frequency and severity but tend to be under-reported in the literature. The extra-biliary complications can be access-related or procedure-related. Different techniques of abdominal access are described but none has been found to be superior in terms of preventing accessrelated injuries [50].

In the field study component of this analysis, we found that $>75 \%$ of respondents have experienced BDI and/or near-misses at some point during their surgical career. Moreover, the ratio was dependent on the number of life-time cases of cholecystectomies and it reached $>80 \%$ among surgeons who had performed $>1,000$ cases, which was similar to the observation by Massarweh et al. [51].

Operators appear to interpret their deficit in visual information based on what they "like to" see (i.e. cystic duct) rather than what they "don't like to" see (i.e. common bile/hepatic duct or the right hepatic duct). A fixed mindset is difficult to correct and it is believed to occur even in cases without severe inflammation and among expert LC surgeons [52].

Although $95 \%$ of the reported cases of bile duct injury are of iatrogenic origin, the incidence of such complications during abdominal surgery is very low. The incidence rate ofan accidental lesion of the common bile duct during routine cholecys- tectomy at 51 Swedish hospitals from 1975: 1981 was recently reported to be only $0.07 \%$ [53]

The two patients with leakage from small biliary radicals were both successfully treated with endoscopically placed stents. Kozarek and Traverso have also reported a case in which a cystic duct leak after laparoscopic cholecystectomy was successfully managed with endoscopic stent placement [54].

The overall acceptance of laparoscopic cholecystectomy you have increased the number of operations performed world wide. Duct injury continues to occur with a prevalence of $0.3-0.6 \%$. The present paper evaluates the survival and quality of life of patients following operative repair [55].

Open cholecystectomy has been associated historically with $0.2 \%$ to $0.5 \%$ risk of postoperative biliary injury. Laparoscopic cholecystectomy, which has become the first line surgical treatment of calculous gallbladder disease, has been associated with a 2.5 fold to fourfold increase in the incidence of postoperative bile duct injury [56]

The biliary endoscopist can expect to see a varied spectrum of complications after cholecystectomy by either technique, including postoperative biliary strictures, bile leaks, and retained calculi in the biliary tree. Proper diagnosis and treatment are paramount in ensuring a satisfactory outcome after bile duct injury. Endoscopic retrograde cholangio-pancreatography (ERCP) has become the primary modality for treatment and effectively manages most bile duct injuries [57]

Approximately $75 \%$ of the BDI identiied in our study were identifies the current management practice of such injuries. The indings of more recent studies combined with our indings strongly suggest that laparoscopic cholecystectomies are no longer more prone to BDI compared to an open approach [58]

Once the correlation between the laparoscopic approach and increased BDI rates was established in the literature, a plethora of theories for this inding were ofered. Many pub-lications concluded that the laparoscopic "learning curve" was the etiology of the increased BDI rates [59].

Conversion to an open procedure is a frequently taught alternative option during a diicult laparoscopic dissection or when a BDI is suspected. There is limited research regarding performing open cholecystectomies in the laparoscopic era, but the paucity of studies currently suggests an 
increased risk of BDI in cases when a conversion form a laparoscopic to an open approach occurs [60].

That ending could be due to the lack of open cholecystectomy experience with the younger surgical generation leading to a greater likelihood of a BDI when a procedure is converted. Alternatively, this could reelect the altered anatomy and generally increased technical diiculty of these operations. Our results found the incidence of a BDI with a converted procedure was an outstanding $15 \%$ [61]

However, LC is associated with a higher incidence of bile duct injury compared to open cholecystectomy, and the incidence of bile duct injury associated with $\mathrm{LC}$ has risen from about $0.15 \%$ to $0.6 \%$.

Only $30 \%$ of injuries are identifed intraoperatively, and the majority present postoperatively with non-specifc symptoms [62]

When the injuries are minor, by cold mechanisms and thin biliary ducts, the recommendation is primary suture and placement of abdominal drains in the area. The reconstruction with end to end anastomosis of the main bile duct with a $\mathrm{T}$ tube is recommended in cases of exten-sive or complete sections without thermal injury. In the current series, because of the type of injuries and the mechanisms involved, the most commonly used procedure was primary suture with decompression of the biliary tract [63].

Early biliary strictures developed in 2 patients and were re-treated satisfactorily with excellent results. Thermal injury in one patient and ischemia by devascularization in the other had direct implications on the development of stenosis [64].

The advantages of the intraoperative repair approach are the following: It is performed during the same anesthesia, avoids referring the patient to another institution, total hospitalization is shorter compared with delayed treatment, it generally requires few abdominal and biliary drains, and generates less psychological trauma for the patient. These events generate less discomfort to the patients and their family and are probably less likely to make malpractice litigations [65].

Bile duct injuries and subsequent leaks can occur following laparoscopic and open cholecystectomies and also during other hepatobiliary surgeries. Various patient related and technical factors are implicated in the causation of biliary injuries. Over a period of twenty five years managing such patients of biliary injuries our team has found a practical approach to assess the cause of biliary injuries based on the symptoms, clinical examination and imaging. Bismuth classification is helpful in most of the cases [66]

Sahajpal examinedfactors influencing outcomes of repair in a large retrospective study of LC associated BDIs and concluded that repairs in the intermediate period after injury (72 hours) were associated with increased incidence of strictures compared to the immediate and delayed (more than 6 weeks) repairs [67].

\section{Conclusions:}

Our study demonstrates that advanced laparoscopic fellowship training may decrease conversion rates of laparoscopic cholecystectomy. This may translate into a slightly shorter duration of hospitalization for these patients, which for a high volume procedure could make a significant impact on hospital economics. Nevertheless, further studies are necessary to further elucidate the benefits of formal advanced laparoscopic fellowship training.

\section{References}

1- THOMSON B.N., NARDINO B., GUMM K., ROBERTSON A.J., KNOWLES B.P., COLLIER N.A., et al.: Management of blunt and penetrating biliary tract trauma. J. Trauma Acute Care Surg., 72: 1620-1625, 2016.

2- BHATTACHARJEE P.K.: Bile duct injuries: Mechanism and prevention. Indian J. Surge., 67: 73-77, 2015.

3- GIGER U., OUAISSI M., SCHMITZ S.F., KRÄHENBÜHL S. and KRÄHENBÜHL L.: Bile duct injury and use of cholangiography during laparoscopic cholecystectomy. Br. J. Surg., 98: 391-396, 2014.

4- PERINI R.F., UFLACKER R., CUNNINGHAM J.T., SELBY J.B. and ADAMS D.: Isolated right segmental hepatic duct injury following laparoscopic cholecystectomy. Cardiovasc. Intervent Radiol., 28: 185-195, 2015.

5- EIKERMANN M., SIEGEL R., BROEDERS I., DZIRI C., FINGERHUT A., GUTT C., JASCHINSKI T., NASSAR A., PAGANINI A.M., PIEPER D., TARGARONA E., SCHREWE M., SHAMIYEH A., STRIK M. and NEUGEBAUER E.A.M.: Prevention and treatment of bile duct injuries during laparoscopic cholecystectomy: The clinical practice guidelines of the European Association for Endoscopic Surgery (EAES) Surg. Endosc., 26: 3003-3039, 2012.

6- ADLER D.G., PAPACHRISTOU G.I., TAYLOR L.J., McVAY T., BIRCH M., FRANCIS G., ZABOLOTSKY A., LAIQUE S.N., HAYAT U., ZHAN T. and DAS R. Clinical outcomes in patients with bile leaks treated via ERCP with regard to the timing of ERCP: A large multicenter study. Gastrointestinal Endoscopy, 85 (4): 766-72, 2017. 
7- FORTUNATO A.A., de ALMEIDA GENTILE J.K., CAETANO D.P., GOMES M.A. and BASSI M.A.: Comparative analysis of iatrogenic lesion of bile ducts in conventional and videolaparoscopic cholecystectomies. Rev. Med. Minas Gerais., 24 (4): 454-7, 2014.

8- REDWAN A.A.: Surgery vs. Endoscopy Competitive or Complementary Tools for Management of Post Cholecystectomy Problems 10 Years' Experience in Major Referral Center. J. Gastroint Dig. Syst., 4 (167): 2, 2014.

9- ZORIČ I’C I, SOLDO I., SIMOVI’C I., SEVER M., BAKULA B., GRBAVAC M., MARUCI'c M. and SOLDO A.: Common bile duct stricture after laparoscopic cholecystectomy: Case Report Acta. Clin. Croat, 56: 179-182, 2017.

10- XIAOBIN FENG and JIAHONG DONG: Surgical management for bile duct injury BioScience Trends, 11 (4): 399-405, 2017.

11- ZHILEI CHENG, XIAOQIANG HUANG, JIAHONG DONG: A Promising Method for Repairing Low-Level Biliary Strictures After Cholecystectomy Int. Surg., 100: 1072-1077, 2015.

12- MONTALVO-JAVÉ E.E., MENDOZA BARRERA G.E., VALDERRAMA TREVIÑO A.I., PIÑA BARBA M.C., MONTALVO-ARENAS C., ROJAS MENDOZA F., LEÓN MANCILLA B., GARCÍA PINEDA M.A., JAIME LIMÓN Á., ALBORES SAAVEDRA J. and TAPIAJURADO J.: Absorbable bioprosthesis for the treatment of bile duct injury in an experimental model International Journal of Surgery, 20: 163e169, 2015.

13- RAINIO M., LINDSTRÖM O., UDD M., HAAPAMÄKI C., NORDIN A. and KYLÄNPÄÄ L.: Endoscopic Therapy of Biliary Injury After Cholecystectomy Dig. Dis. Sci., 2017.

14- CHITTAPURAM S., BABU S. and SHARMA M.: Biliary Tract Anatomy and its Relationship with Venous Drainage J. Clin. Exp. Hepatol., 4: S 18-S26, 2014.

15- SHAUN McKENZIE and RICHARD SCHWARTZ: The Management of Bile Duct Injuries Occurring During Laparoscopic Cholecystectomy (c) 2006 by the Association of Program Directors in Surgery 0149-7944/06/\$30.00 Published by Elsevier Inc. doi:10.1016/ j. cursur. 2005.06.001

16- GUUSZEK S, KOT M., BAĹCHANOWSKI N., MATYKIEWICZ J., KUCHINKA J., KOZIELD. and WAWRZYCKA I.: IAtROGENIC bILE duCt INjuRIES - CLINICAL PRObLEMS Pol Przegl Chir., 86 (1): 17-25, 2014.

17- MEHMET KARABULUT, MURAT GÖNENÇ and HALIL ALiÇ: The chain of postoperative complications after laparoscopic cholecystectomy Ulusal Cer Derg., 30: 173-5, 2014.

18-MOUSTAFA A., KADER A. WAHAB, ENAS A. ABDELGAWAD, ABDEL FATAH SALEH and MEDHAT M. SULIMAN: Magnetic resonance cholangiopancreatography (MRCP) evaluation of post-laparoscopic cholecystectomy biliary complications using breath-held 3D steady state free precession (SSFP) sequence The Egyptian Journal of Radiology and Nuclear Medicine, 47: $207-$ 216, 2016.

19-RAM SHRINGAR DUBEY, OP PANDEY: Evaluation of the Treatment Outcomes in cases with Bile Leakage following Cholecystectomy HECS International Journal of Community Health and Medical Research, Vol. 4, Issue 2, April-June 2018.

20- JI HUN KIM, WOOK HWAN KIM, JIN HONG KIM, BYUNG MOO YOO and MYUNG WOOK KIM: Management of Patients Who Return to the Hospital with a Bile Leak After Laparoscopic Cholecystectomy Journal of Laparoendoscopic \& Advanced Surgical Techniques Volume 20, Number 4, 2010.

21- THOMAS B. HUGH: Australia New strategies to prevent laparoscopic bile duct injury-surgeons can learn from pilots Surgery, 132: 826-35, 2002.

22- VINAY K.: Kapoor Bile duct injury repair: When? what? who? J. Hepatobiliary Pancreat Surg., 14: 476-479, 2007.

23- MARIANO PALERMO, NELSON TRELLES and MICHEL GAGNER: Laparoscopic Revisional Hepaticojejunostomy for Biliary Stricture After Open Repair Following Common Bile Duct Injury: A Case Report Surgical Innovation 18(1) 105 -109 @ The Author(s) 2011 .

24- REDWAN A.A.: Complex Post-cholecystectomy Biliary Injuries: Management with 10 Years' Experience in a Major Referral Center Journal of Laparoendoscopic \& Advanced Surgical Techniques Volume 22, Number 6, 2012.

25- BERISTAIN-HERNANDEZ JOSE-LUIS: Current controversies in management of bile duct injuries J. Liver Res. Disord Ther., 2 (2):41-42, 2016.

26- LYGIA STEWART and LAWRENCE W.: Way Laparoscopic bile duct injuries: Timing of surgical repair does not influence success rate. A multivariate analysis of factors influencing surgical outcomes HPB, 11: 516-522, 2009.

27- CHANDIKA LIYANAGE and MPHIL M.S. M.R.C.S (Eng.): Laparoscopic cholecystectomy: Are we being safe? The Sri Lanka Journal of Surgery, 31 (1): 12-14, 2013.

28- APURVA KUMAR RAJAN and SOHAIL ANJUM: A study on post operative bile leak after cholecystectomy in JLNMC, Bhagalpur Original research paper international Journal of scientific research Volume-6, issue-7, July, ISSN No 2277-8179, IF : 4.176, IC Value: 78.46, 2017.

29- ViRINDER K. BANSAL, ASURI KRISHNA, MAHESH C. MISRA, PREM PRAKASH, SUBODH KUMAR, KARTHIK RAJAN, DIVYA BABU, PRAMOD GARG, ATIN KUMAR and RAJESHWARI S.: Factors Affecting Short-Term and Long-Term Outcomes After Bilioenteric Reconstruction for Post-cholecystectomy Bile Duct Injury: Experience at a Tertiary Care Centre Indian J. Surg., 2013.

30- STÉPHANIE TRUANT, EMMANUEL BOLESLAWSKI, GILLES LEBUFFE, GÉRALDINE SERGENT and FRANÇOIS-RENÉ PRUVOT: Hepatic resection for postcholecystectomy bile duct injuries: A literature review HPB, 12: 334-341, 2010.

31- MIGUEL ÁNGEL MERCADO, BERNARDO FRANS SEN, ISMAEL, JUAN CARLOS ARRIOLA-CABRERA, FERNANDO RAMíREZ-DEL VAL, ALEJANDRO ELNECAVÉ-OLAIZ, RIGOBERTO ARÁMBURO-GARCíA and ARTEMIO GARCíA: Transition from a low- to a high-volume centre for bile duct repair: Changes in 
technique and improved outcome HPB, 13: 767-773, 2011.

32- FRANCISCO JAVIER GONZALEZ, ELIAS DOMINGUEZ, ANGEL LEDE, PORTELA JOSE and PIÑON MIGUEL: Migration of vessel clip into the common bile duct and late formation of choledocholithiasis after laparoscopic cholecystectomy The American Journal of Surgery, 202: e41-e43, 2011.

33- CHRISTOPHE R. BERNEY: Major common bile duct injury and risk of litigation: A surgeon's perspective The American Journal of Surgery, 204: 800-802, 2012.

34- ELIZABETH J.LILLEY, JOHN W.SCOTT, WEI JIANG, ANNA KRASNOVA, NIKHILA RAOL, NAVIN CHANGOOR, ALI SALIM, ADIL H. HAIDER, JOEL S. WEISSMAN, ERIC B. SCHNEIDER and ZARA COOPER: Intraoperative cholangiography during cholecystectomy among hospitalized medicare beneficiaries with non-neoplastic biliary disease The American Journal of Surgery 214: 682e686, 2017.

35- GURTESHWAR RANA, M.D., JASNEET SINGH BHULLAR, M.D., GOKULAKKRISHNA SUBHAS, M.D., R.B.KOLACHALAM, M.D., V. K. MITTAL, M.D. NING SUN, JIALIN ZHANG, CHENGSHUO ZHANG and YUE SHI: Single-site robotic cholecystectomy versus multiport laparoscopic cholecystectomy: A systematic review and meta-analysis The American Journal of Surgery 216: $1205 \mathrm{e} 1211,2018$.

36- MUBASHIR H. KHAN, M.D., THOMAS J. HOWARD, M.D., EVAN L. FOGEL, M.D., STUART SHERMAN, M.D., LEE McHENRY, M.D., JAMES L. WATKINS, M.D., DAVID F. CANAL, M.D., GLEN A.LEHMAN, M.D.: Frequency of biliary complications after laparoscopic cholecystectomy detected by ERCP: Experience at a large tertiary referral center Gastrointest Endosc.,65: 247-52, 2007.

37- VIJAI PRAKASH SRIVASTAVA, SHWETANK AGARWAL, AJAI AGARWAL, JAGADAMBA SHARAN: Managing bile duct injuries sustained during cholecystectomies International Surgery Journal Srivastava V.P., et al. Int. Surg. J. Jan., 5 (1): 148-152, 2018.

38- AMMAR SABAH, HUSSEIN ALI ALKUMASI and MOHAMMED REDA AL GHADHBAN: Incidence of major biliary injuries associated with laparoscopic cholecystectomy at Al-Karama teaching hospital, Baghdad, Iraq International Surgery Journal Sabah A., et al. Int. Surg. J. Mar., 5 (3): 827-833, 2018.

39- YASSER FOUAD: Kilany efficacy of endoscopic retrograd cholangiopancreatography (ercp) management of early and late bile duct complications after cholecystectomy with retrospective study Al-Azhar Assiut Medical Journal Vol. 13, No. 2, April Suppl. 2, 2015.

40- AL HAJJAR N., TOMUæ C., MOCAN L., MOCAN T., GRAUR F., IANCU C. and ZAHARIE F.: Management of Bile Duct Injuries Following Laparoscopic Cholecystectomy: Long-term Outcome and Risk Factors Infuencing Biliary Reconstruction Chirurgia, 109: 493-499 No. 4, July-August Copyright $\odot$ Celsius, 2014.

41- GARY C. VITALE, M.D., F.A.C.S., TIN C. TRAN, M.D., BRIAN R. DAVIS, M.D., MICHAEL VITALE, M.D., DAVID VITALE, B.S. and GERALD LARSON, M.D., F.AC.S. NDOSCOPIC: Management of Postcholecystec- tomy Bile Duct Strictures J. Am. Coll. Surg., 206: 918925. (C) 2008, 2008.

42- ASHWANI KUMAR UPASNA KUMAR ANAND MUNGHATE ASHVIND BAWA: Role of routine intraoperative cholangiography during laparoscopic cholecystectomy Surg. Endosc., 29: 2837-2840, 2015.

43- ANTONIO IANNELLI, JACQUES PAINEAU, ANTOINE HAMY, ANNE-SOPHIE SCHNECK, CAROLINE SCHAAF and JEAN GUGENHEIM: Primary versus delayed repair for bile duct injuries sustained during cholecystectomy: Results of a survey of the Association Francaise de Chirurgie HPB, 15: 611-616, 2013.

44- RUSSELL C. KIRKS, T.E. BARNES, PATRICK D. LORIMER, ALLYSON COCHRAN, IMRAN SIDDIQUI, JOHN B. MARTINIE, ERIN H. BAKER, DAVID A. IANNITTI and DIONISIOS VROCHIDES: Comparing early and delayed repair of common bile duct njury to identify clinical drivers of outcome and morbidity HPB, 18: 718-725, 2016.

45- MOSTAFA A. HAMAD, AHMAD A. NADA, MOHAMAD Y. ABDEL-ATTY and AHMAD S. KAWASHTI: Major biliary complications in 2, 714 cases of laparoscopic cholecystectomy without intraoperative cholangiography: A multicenter retrospective study Surg. Endosc., 25: $3747-$ 3751, 2011.

46- TÖRNQVIST B., WAAGE A., ZHENG Z., YE W. and NILSSON M.: Severity of Acute Cholecystitis and Risk of Iatrogenic Bile Duct Injury During Cholecystectomy, a Population-Based Case-Control Study World J. Surg., 40: 1060-1067, 2016.

47- FLOYD W. van de GRAAF, INA ZAÏMI, LAURENTS P.S. STASSENB, JOHAN F. LANGEA: Safe laparoscopic cholecystectomy: A systematic review of bile duct injury prevention International Journal of Surgery, 60: 164-172, 2018.

48- HOGAN N.M., DORCARATTO D., HOGAN A.M., NASIRAWAN F., MCENTEE P., MAGUIRE D., GEOGHEGAN J., TRAYNOR O., WINTER D.C. and HOTI E.: Iatrogenic common bile duct injuries: Increasing complexity in the laparoscopic era: A prospective cohort study International Journal of Surgery, 33: 151e156, 2016.

49- ANNE WAAGE, M.D., Ph.D. and MAGNUS NILSSON, M.D., Ph.D.: Iatrogenic Bile Duct Injury A PopulationBased Study of 152776 Cholecystectomies in the Swedish Inpatient Registry Arch. Surg., 141: 1207-1213, 2006.

50- ARIAN M. NIKPOUR, M.D., MPH R. JUSTIN KNEBEL, M.D. and DANNY CHENG, M.D.: Diagnosis and Management of Postoperative Biliary Leaks Seminars in Interventional Radiology, Vol. 33 No. 4, 2016.

51- AHMAD M. SULTAN, AYMAN M. ELNAKEEB, MOHAMED M. ELSHOBARY, AHMED A. EL-GEIDI, TAREK SALAH, EHAB A. EL-HANAFY, EHAB ATIF, EMAD HAMDY and GAMAL K. ELEBIEDY: Management of post-cholecystectomy biliary fistula according to type of cholecystectomy Sultan Ahmad M., et al., ERCP for post-cholecystectomy biliary fistula... Endoscopy International Open, 03: E91-E98, 2015.

52- PRASANTI G. VACHHANI, M.D., ALEXANDER COPELAN, M.D., ERICK M. REMER, M.D. and FACR BALJENDRA KAPOOR M.D., FSIR: Iatrogenic Hepat- 
opancreaticobiliary Injuries: A Review Semin Intervent Radiol., 32: 182-194, 2015.

53- LI L.J., ZHENG X.M., JIANG D.Z., ZHANG W., SHEN H.L., SHAN C.X., LIU S. and QIU M.: Progress in laparoscopic anatomy research: A review of the Chinese literature. World J. Gastroenterol., 16 (19): 2341-2347, 2010.

54- YUNFENG CUI, HONGTAO ZHANG, NAIQIANG CUI and ZHONGLIAN LI: Surgical treatment for benign biliary strictures: Single-center experience on 64 cases excli Journal, 11: 390-398 - ISSN 1611-2156, 2012.

55- SEZGIN YILMAZA, MURAT AKICI, NAZAN OKURB and SERKAN TÜREL: Spontaneous postoperative choledochoduodenal fistula due to bile duct injury following laparoscopic cholecystectomy International Journal of Surgery Case Reports, 25: 199-202, 2016.

56- FRANCISCO RUIZ GÓMEZ, JOSÉ MANUEL RAMIA ÁNGEL, JORGE GARCÍA-PARREÑO JOFRÉ and JOAN FIGUERAS: Iatrogenic bile duct injuries. CIR ESP, 88 (4): 211-221, 2010.

57- ABDELRAHIM W.E., KAMAL ELSIDDIG E., WAHAB A.A., SAAD M., SAEED H. and KHALIL E.A.G.: Subtotal laparoscopic cholecystectomy influences the rate of conversion in patients with difficult laparoscopic cholecystectomy: Case series Annals of Medicine and Surgery 19: 19e22, 2017.

58- ARSHAD M. MALIK, ABDUL AZIZ LAGHARI, ALTAF HUSSAIN TALPUR and ASAD KHAN: Iatrogenic biliary injuries during laparoscopic cholecystectomy. A continuing threat International Journal of Surgery, 6: 392-395, 2008.

59- SILVIA QUARESIM, ANDREA BALLA, MARIO GUERRIERI, ROBERTO CAMPAGNACCI, EMANUELE LEZOCHE and ALESSANDRO M.: Paganini A 23 year experience with laparoscopic common bile duct exploration HPB, 19: 29-35, 2017.

60- RAVICHANDRA MATCHA and MYTHILIDEVI: Sappa bile duct injuries following laparoscopic cholecystectomya retrospective study at government general hospital, kakinada J. Evid. Based Med. Healthc., 4 (91): 54705473,2017
61- CORI-ANN M. HIRAI, M.D.; DANIEL MURARIU M.D., MPH; MATTHEW D. COOPER M.D.; ANDREW J. OISHI M.D.; STEVEN D. NISHIDA M.D.; CEDRIC S.F. LORENZO M.D. and RACQUEL S. BUENO, M.D., FACS: Single-incision Laparoscopic Cholecystectomy at Community Hospitals in Honolulu, Hawai: A Case Series Hawai'I Journal of Medicine \& Public Health, December, Vol. 72, No. 12 428, 2013.

62- HISHAAM N. ISMAEL, STEVEN COX, AMANDA COOPER, NISHA NARULA and THOMAS ALOIA: The morbidity and mortality of hepaticojejunostomies for complex bile duct injuries: A multi-institutional analysis of risk factors and outcomes using NSQIP HPB, 19: 352$358,2017$.

63- MELISSA M. MURPHY, M.D., MPH, SING-CHAU NG, M.S., JESSICA P. SIMONS, M.D., MPH, NICHOLAS G. CSIKESZ, M.D., SHIMUL A. SHAH, M.D., FACS and JENNIFER F. TSENG, M.D., MPH, FACS: Predictors of Major Complications after Laparoscopic Cholecystectomy: Surgeon, Hospital, or Patient? by the American College of Surgeons Published by Elsevier Inc., 2010.

64- BOBKIEWICZ A., KROKOWICZ 'L , BANASIEWICZ T., KOS'CIN'SKI T, BOREJSZA-WYSOCKI M., LEDWOSIN'SKI W. and DREWS M.: Iatrogenic bile duct injury. A significant surgical problem. Assessment of treatment outcomes in the department's own material. Pol. Przegl Chir., Mar. 1; 86 (12): 576-83, 2015.

65- MICHAEL R. PHILLIPS, MARK JOSEPH, EVAN S. DELLON, IAN GRIMM, TIMOTHY M. FARRELL and CHRISTOPHER C. RUPP: Surgical and Endoscopic Management of Remnant Cystic Duct Lithiasis After Cholecystectomy-a Case Series J. Gastrointest Surg., 2014.

66- PETER A.: Wysocki Population-Based Studies Should not be Used to Justify a Policy of Routine Cholangiography to Prevent Major Bile Duct Injury During Laparoscopic Cholecystectomy World J. Surg., 41: 82-89, 2017.

67- YOON H.A., NOH M.H., KIM B.G., et al.: Clinicopathological significance of altered Notch signaling in extrahepatic cholangiocarcinoma and gallbladder carcinoma. World J. Gastroenterol., 17 (35): 4023-30, 2011. 


\section{تشخيص وعلاج حالات إصابة القنوات المرارية

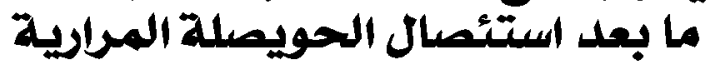

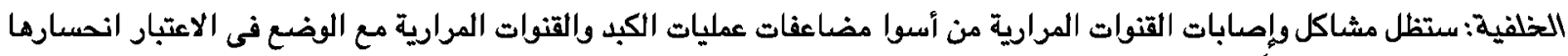

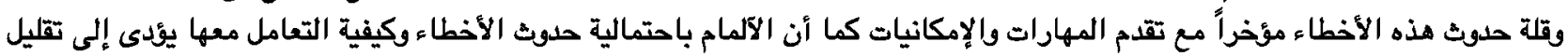

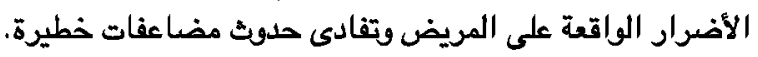

الهدف: متابعة وتقييم توقيت ونتائج التد خل الجراحى لإصلاح إصابات القنوات المرارية الناتجة عن خطأ الجراح أثناء العمليات الجراحية

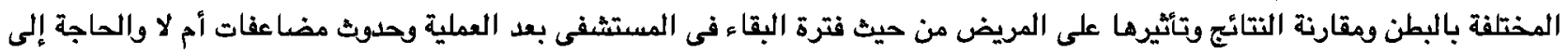
التخخل مرة أخرى أو المتابعة.

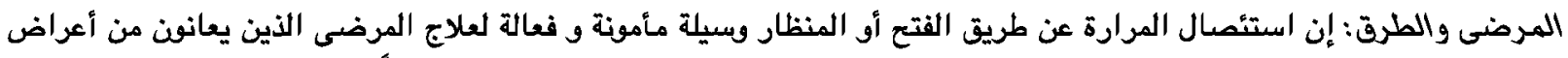

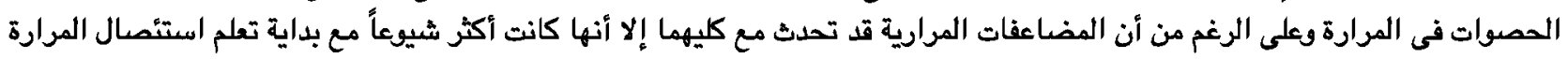

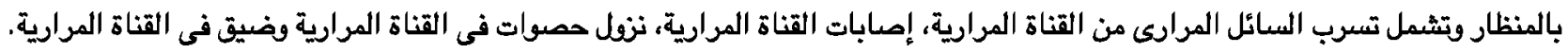

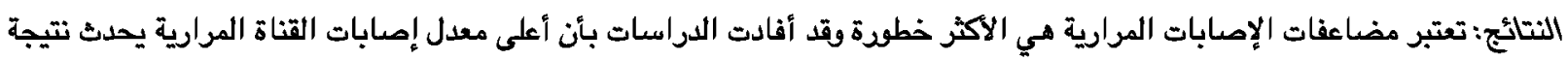

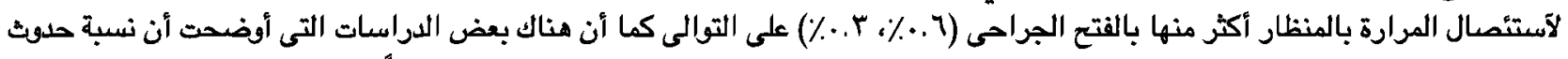

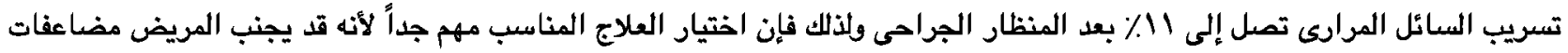

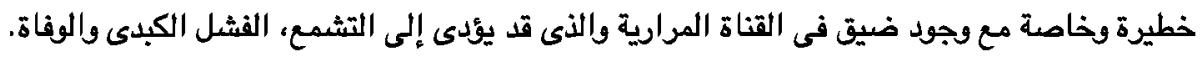

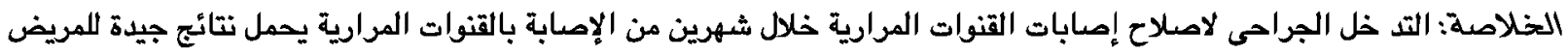

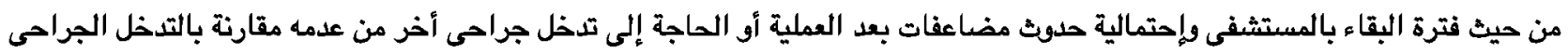

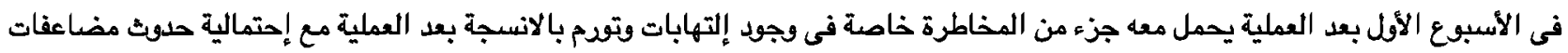

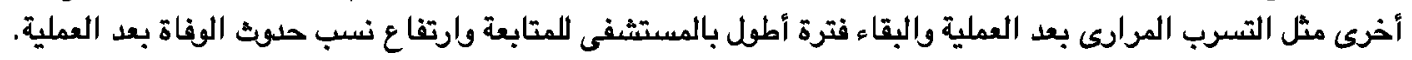

